\title{
Safeguarding the future of sleep medicine, research, and education
}

\author{
Clete A. Kushida
}

This editorial launches the journal, Sleep Science and Practice, which is an open access peer-reviewed journal for clinicians and researchers interested in the study of sleep and sleep medicine. The mission of this journal is to basic, clinical and translational sleep-related research that assists sleep specialists, scientists, and other professionals worldwide with their research and patient-care activities. The journal's scope includes basic sleep concepts, sleep anatomy, physiology and pharmacology, sleep assessment, sleep disorders, sleep issues related to other conditions and disorders, and sleep in special populations.

For the launch of Sleep Science and Practice, I thought it would be appropriate to select a topic that many people whom are involved in the field have in the back of their minds. Anyone who has been involved in sleep medicine for a while has probably been asked his or her opinion of where the field is headed and what can be done to safeguard its future. Our field is in transition, and the future is complex, but if one has been in the field long enough, then he or she has noticed trends over time that would enable one to make some educated guesses for the field in the years ahead. This editorial pertains only to sleep medicine, research, and education in the United States; sleep medicine elsewhere is more diverse in reimbursement and type of practice styles.

Here are predictions for the future and what can be done to ensure a successful outcome in various domains within the field of sleep; only the passage of time will reveal their accuracy and it is hoped that this editorial will stimulate others to join in on this discussion.

\section{The clinical practice of sleep medicine}

Many sleep specialists have stated that one of the major limitations of our field is its dependence on one procedure, in-laboratory polysomnography; declining insurance reimbursement for polysomnography has led to contraction of our clinical services nationwide due to collapse of some sleep laboratories (Quan \& Epstein 2013). In-laboratory sleep studies will most likely continue to be conducted in large hospital networks and academic medical centers but will be further restricted for sleep and/or medically complex patients, the diagnosis of patients with sleep disorders other than obstructive sleep apnea, and titration of devices other than continuous positive airway pressure (CPAP) such as auto-servoventilation.

Instead of traditional out-of-center (home) sleep testing, there will probably be an evolution to small, compact medical devices adapted from consumer wearable devices and smartphone apps that will use technology such as heart rate variability combined with other measures to enable the accurate and reliable diagnosis of sleep-related breathing disorders. More engagement of sleep specialists with industries that develop sleep-related devices may ensure that sleep clinicians are actively involved throughout the development process so that the finished products are validated and meet the needs of sleep clinics.

The increased use of home sleep testing will most likely cause a greater shift in the workforce at sleep centers, resulting in less sleep technologists and more advanced practice providers to manage clinical visits of more medically complicated patients. Automatic sleep scoring will become routine for in-laboratory sleep studies as well as for home sleep testing. Telemedicine will become more established within sleep medicine, where patients on positive airway pressure and other devices can be more easily and remotely managed. There will be a shift more toward cognitive behavioral treatment for insomnia (CBTI) by advanced practice providers, and Internet-based CBTI to address the huge demand for this therapy.

I believe that there will be better treatments for OSA, perhaps stem cells and fetal surgery can someday be used to treat defects in the upper airway. Lastly, it would be expected that primary care and otolaryngology will also increase their management of more patients with sleep disorders. 


\section{Sleep-related research}

It is reasonable to predict that funding from the National Institutes of Health will probably continue to be cyclic. As less federal research dollars are available, researchers will most likely turn to industry, foundations, sleep professional organizations, and other funding sources to support their basic and clinical research in sleep. These sources of funding can be less predictable, and especially in the case of industry, funds can be abruptly reduced or canceled depending on the quarterto-quarter success of the company or their priority changes at any given time. These funding sources can also be limited to certain demographics of researchers, and the funders may not have the budgets to accommodate largescale projects. However, these funders may have less restrictions and less stringent reporting requirements compared to federal funding sources.

For early career investigators, these sources may provide adequate funds to plan and conduct a preliminary study, and successful results from this study in turn can be used to gain funds for a larger study and/or provide necessary statistical power for sample size estimates to launch a multicenter controlled trial. It is incumbent on the leadership of sleep professional organizations to prioritize funding for strategic research initiatives to ensure continued growth of the field, and to explore the development of research networks that will enable junior and experienced investigators to conduct high quality research through multidisciplinary and diverse regional collaborations.

\section{Education in sleep medicine}

It is likely that the number of candidates applying to Accreditation Council for Graduate Medical Education (ACGME) sleep medicine fellowships will continue to decrease. Additionally, sleep medicine fellowship programs will most likely decrease in size due to unfilled Sleep Medicine fellowship match positions (Quan 2013), with this trend persisting until fellowship programs reach an equilibrium point, most likely limited to 1-2 fellows per large academic institution.

The decreased applications from new sleep fellowship candidates is most likely due to decreased salaries and fewer job opportunities for these clinicians. However, it is predictable that within a few years there will be a restructuring of the role of the sleep specialist, given some of the market and scientific factors discussed in the prior section above on The Clinical Practice of Sleep Medicine. This new role will probably involve more interdisciplinary relationships, resulting in more outpatient and inpatient consults in other hospital departments.

Sleep professional organizations must take an active role in encouraging students to enter into the field, perhaps starting even as early as high school. The ability of these organizations to provide high-quality sleep clinical educational and training opportunities will further stimulate interest in medical residents to pursue another year of their training within the field of sleep medicine.

\section{Conclusions}

Sleep medicine is not immune to the problems facing other disciplines of medicine at times of political and economic uncertainty. Fortunately, the uniqueness of our field in its multidisciplinary nature is also its strength; for example, sleep specialists will be able to use their primary specialty training (e.g., internal medicine, neurology, pulmonary medicine, psychiatry, pediatrics) to weather the storm during periods of economic downturn by managing not only patients with sleep disorders but also patients in clinical settings focused on diseases that are within the scope of their primary specialty training. However, I firmly believe that experienced clinicians and researchers must take ownership of pieces of the issues and problems facing the field in order for the field to continue to flourish. There are many possible solutions to the challenges that our field currently faces; for the growing number of clinicians and scientists who have a passion for sleep medicine, research, and education, these challenges represent tremendous opportunities for us to formulate new ideas, visions, and plans on how to best evolve our field to further ensure its continued success.

Received: 22 December 2016 Accepted: 22 December 2016 Published online: 06 February 2017

References

Quan SF, Epstein LJ. A warning shot across the bow: the changing face of sleep medicine. J Clin Sleep Med. 2013;9(4):301-2.

Quan SF. Graduate medical education in sleep medicine: did the canary just die? J Clin Sleep Med. 2013;9(2):101.

Submit your next manuscript to BioMed Central and we will help you at every step:

- We accept pre-submission inquiries

- Our selector tool helps you to find the most relevant journal

- We provide round the clock customer support

- Convenient online submission

- Thorough peer review

- Inclusion in PubMed and all major indexing services

- Maximum visibility for your research

Submit your manuscript at www.biomedcentral.com/submit ) BioMed Central 